\title{
DESPLAZAMIENTO Y VIGENCIA DEL MAPUDUNGÚN EN CHILE: UN ANÁLISIS DESDE EL DISCURSO REFLEXIVO DE LOS HABLANTES URBANOS*
}

\author{
LANGUAGE SHIFT AND MAINTENANCE OF MAPUDUNGUN \\ IN CHILE: AN INSIGHT FROM URBAN SPEAKERS' REFLEXIVE \\ DISCOURSE
}

\author{
FERNANDO WITTIG G.** \\ Universidad de Concepción. Chile \\ fwittig@udec.cl
}

\section{RESUMEN}

La migración urbana propicia nuevos procesos de construcción de la identidad étnica en la comunidad mapuche en Chile. Con esta consideración, proponemos una nueva mirada a las condiciones de uso y transmisión del mapudungún en contexto urbano, en el escenario de desplazamiento lingüístico que afecta a esta lengua en su condición de lengua dominada o idioma oprimido. La base empírica de la investigación proviene de entrevistas semi-estructuradas con hablantes urbanos de Santiago, Temuco y Concepción durante 2006 y 2007. Las representaciones sobre episodios autobiográficos permiten configurar un itinerario de análisis que se centra en: los espacios sociales favorables para el uso del mapudungún, y las nuevas experiencias de adquisición y recuperación de la lengua. A través de la reflexión y el testimonio de los hablantes es posible constatar eventuales procesos de cambio sociocultural y resistencia étnica que buscan compensar el modelo diglósico imperante que limita las opciones de uso del mapudungún en el contexto urbano chileno.

Palabras clave: Desplazamiento lingüístico, mapudungún, mapuches urbanos de Chile, identidad étnica, resistencia étnica.

\footnotetext{
* A través de esta nota quiero agradecer los valiosos comentarios que hicieron a versiones preliminares de este texto mis colegas Gerardo Álvarez, Rodrigo Becerra, Edson Faúndez, Aldo Olate, José Manuel Rodríguez y Gabriel Simmunovic, en estricto orden alfabético.

** La investigación en la que se enmarca este artículo ha sido posible gracias al financiamiento que me han otorgado CONICYT y la Escuela de Graduados de la Universidad de Concepción para la realización de mis estudios doctorales en lingüística.
} 


\begin{abstract}
Urban migration triggers new processes of ethnic identity among mapuche people in Chile. Given this, we propose a new approach towards the conditions that rules the use and transmission of mapudungun among urban speakers in the context of a general linguistic shift process. The empirical base of the investigation was obtained in semi-structured interviews with urban speakers of mapudungun in Santiago, Temuco and Concepcion, between 2006 and 2007. The representations about autobiographic episodes make possible to follow an analytical path that focuses on the social spaces identified for the use of mapudungun, and the new experiences of acquisition and re-use of the language. We state that through the speakers' testimony it is possible to reveal processes of socio-cultural change and ethnic resistance that seeks to counterbalance the diglossic model that rules the use options of mapudungun in the Chilean urban setting.
\end{abstract}

Keywords: Language shift, mapudungun, urban mapuche in Chile, ethnic identity, ethnic resistance.

Recibido: 06-11-2008. Aceptado: 21-05-2009.

\title{
1. INTRODUCCIÓN
}

as investigaciones que describen las condiciones de uso del mapudungún y se han enfocado en el contexto rural de las comunidades o reducciones. Sólo en los últimos años se han materializado los primeros esfuerzos por caracterizar las pautas de uso y transmisión del mapudungún en la población urbana. La premisa general es que el éxodo de las comunidades a la ciudad conlleva una disminución irreversible del uso del mapudungún entre la población migrante. Esta posición se fundamenta en la estrecha relación que existe entre la lengua y las pautas culturales tradicionales, y ha quedado cristalizada en la conocida fórmula "hablar en mapuche es vivir en mapuche" (Salas, 1987). En opinión de Salas, los mapuches urbanos dejarían de ser "socioculturalmente mapuches", puesto que en la ciudad se castellanizan y asumen modos de vida que los asimilan al resto de la población chilena.

Según investigaciones recientes ${ }^{1}$, el mapudungún se encuentra en una fase de desuso progresivo: su número de hablantes disminuye, el uso del español se extiende hasta en los ámbitos tradicionales, el quiebre de la transmisión intergeneracional adquiere niveles críticos, la lengua no logra adaptarse a las nuevas funciones comunicativas que supone el contexto urbano. En los últimos años hemos mantenido un contacto permanente con hablantes de mapudungún, académicos mapu(2008).

${ }^{1}$ Principalmente Gundermann (2005), Zúñiga (2007), Giannelli (2008a) y Gundermann et al. 
ches, dirigentes urbanos y autoridades tradicionales, quienes desde sus particulares perspectivas reafirman grosso modo el cuadro descrito por las investigaciones formales. No obstante, advierten también sobre prácticas lingüísticas consecuentes, primero, con la valoración de la lengua en tanto símbolo de la cultura mapuche, y segundo, con la condición de lengua amenazada que parece caracterizar al mapudungún, al menos en lo que a funciones comunicativas se refiere. Este artículo constituye un intento por comprender estas prácticas lingüísticas, observándolas en relación con los procesos identitarios que atañen a la población mapuche urbana de Chile.

\section{MIGRACIÓN E IDENTIDAD MAPUCHE URBANA}

Según el último Censo de Población (2002), en Chile viven un poco más de 600 mil mapuches, de los cuales casi un $63 \%$ corresponde a población urbana (más de 377 mil personas). Esta se concentra en la capital del país, con más de 180 mil personas. Otras ciudades donde se concentra la población mapuche en números significativos son Temuco (sobre 30 mil), Concepción (cerca de 20 mil) y Osorno $(\text { sobre } 12 \mathrm{mil})^{2}$.

El proceso migratorio ha experimentado cambios profundos en las últimas décadas, en paralelo con las transformaciones que han moldeado la relación entre los mundos rural y urbano, por una parte, y mapuche y chileno, por otra. Así, de un alejamiento radical de la comunidad de origen que caracterizaba la migración de las primeras generaciones se ha llegado a pautas de integración más dinámicas, gracias a mejores condiciones de acceso a las zonas rurales lejanas, a la presencia de redes familiares y sociales de acogida al migrante y la inserción en actividades económicas que permiten flujos migratorios estacionales o transitorios (Bengoa, 1996; Gundermann y González, 2008).

En el plano sociopolítico, los mapuches urbanos se han posicionado como un nuevo sector dentro de la sociedad mapuche. Su discurso se orienta básicamente hacia la reivindicación de los derechos culturales y políticos interpelando tanto a la sociedad nacional como a la sociedad mapuche 'tradicional' (Ancán, 1994; Marimán, 1997). En este proceso, liderado por los llamados intelectuales mapuches, se consolidan las agrupaciones urbanas como una nueva estructura en la trama de organización social mapuche (Varas Insunza, 2005). Este 'despertar' de la sociedad mapuche urbana surge en un escenario sociopolítico nacional e internacional propicio para la reivindicación de las identidades étnicas y la valoración de la diversidad cultural dentro de las sociedades latinoamericanas (Aravena, 1999; Bengoa, 2000 y 2002).

\footnotetext{
${ }^{2}$ Datos disponibles en www.ine.cl.
} 
La reivindicación de la sociedad mapuche urbana se sustenta también en una nueva concepción de la identidad étnica, sujeta a una reconceptualización constante por los mapuches urbanos en una dialéctica entre el apego a los valores tradicionales, por una parte, y la innovación cultural que demanda el espacio urbano, por otra. La nueva identidad mapuche urbana se funda sobre un conjunto de rupturas, reformulaciones y continuidades con la cultura mapuche tradicional (Curivil, 1999; Aravena, 2002; Peyser, 2003). Esta perspectiva implica una concepción de la identidad en tanto "fenómeno de carácter relacional y evolutivo -además de discursivo- que opera de acuerdo al principio de oposición: es distintiva o diferencial" (Gissi, 2002: 6). La identidad étnica de los mapuches urbanos se construye, entonces, desde una doble diferenciación: en relación con las comunidades, por un lado, y la sociedad chilena urbana, por otra. En el plano teórico del asunto, las bases empíricas de las identidades étnicas deben trasladarse, siguiendo la formulación de Barth (1998 [1969]), desde el repertorio de elementos culturales hacia las formas de organización social que definen las relaciones de pertenencia o exclusión del grupo étnico. La identidad étnica se entiende en función de propiedades y relaciones emergentes, dinámicas y múltiples (Bartolomé, 2006).

\section{DESPLAZAMIENTO LINGÜÍSTICO Y RESISTENCIA CULTURAL}

El desplazamiento lingüístico se presenta cuando en una comunidad bilingüe opera una redistribución sostenida y unidireccional de las funciones sociales asignadas a las lenguas usadas por la comunidad (Fishman, 1982; Fasold, 1996). Este proceso por lo general se presenta en contextos de bilingüismo diglósico, en que al avance de una lengua dominante le corresponde el retroceso de la lengua dominada. En su versión inicial, la diglosia fue concebida como una distribución complementaria estable de los contextos comunicativos en que se utilizan lenguas o variedades lingüísticas que comparten un mismo espacio social (Ferguson, 1974 [1959]). Revisiones posteriores del fenómeno han puesto de relieve la inestabilidad y el carácter conflictivo que implican las situaciones de diglosia. Una diglosia inestable puede derivar en un desequilibrio funcional generalizado entre las lenguas en contacto y eventualmente encaminarse a la sustitución de la lengua de bajo prestigio por la lengua dominante (Fasold, 1996).

Orientando la discusión al ámbito indoamericano, Hamel (1988) concibe los procesos de desplazamiento lingüístico de las lenguas indígenas como el resultado de políticas que intervienen en el escenario sociocultural con el objetivo de transformar la base interpretativa de grupos étnicos o grupos sociales. En opinión de Hamel (op. cit.) lo anterior no necesariamente implica la pérdida de su especificidad en tanto grupo: 
La transformación de la base interpretativa de una cultura consiste sobre todo en una ruptura o, por lo menos, modificación cualitativa de la relación entre el lenguaje y la experiencia cultural acumulada. En la medida en que una política del lenguaje prescribe qué patrones lingüísticos y qué lengua se debe usar en una determinada situación, interviene en las formas de percepción y apropiación de experiencias socioculturales (Hamel, 1988: 45).

En este planteamiento, las lenguas son concebidas como vehículos de una experiencia sociocultural particular. No se trata, pues, de una elección puramente funcional entre códigos lingüísticos disponibles. La base interpretativa a que alude Hamel remite a la relación explícita que un grupo humano (grupo social, étnico, étno-nacional, entre otros tipos de organización posibles) establece entre lenguaje y experiencia, como elementos que articulan el patrimonio cultural del grupo. Con el desplazamiento lingüístico se produce, entonces, un doble proceso: por un lado, se modifica el patrón de usos de las lenguas en cuestión; por otro, se modifican las pautas culturales que regulan las interacciones comunicativas entre los miembros del grupo. Aunque, por lo general, ambos procesos suelen ir encadenados, la relación entre ambos no es necesariamente unívoca.

En el caso mapuche, mapudungún y español son lenguas que coexisten en diversos espacios sociales desde la llegada de los españoles. En esta convivencia no deseada por las partes, a la lengua mapuche le corresponde el rol de "idioma oprimido" (Albó, 1988). La perspectiva de los idiomas oprimidos contempla dimensiones específicas en las cuales queda de manifiesto la agresión que han sufrido las lenguas amerindias en el marco de los procesos históricos de colonización y hegemonía (Calvet 2005 [1974], Zimmermann, 1999). Albó acude a la imagen de la atrofia y la proyecta a tres planos diferentes. En el plano netamente lingüístico remite al empobrecimiento léxico, la pérdida de oposiciones fonológicas y la alteración de rasgos gramaticales considerados sólidos en cada una de estas lenguas. También ejemplifica la atrofia de estos idiomas en "la inoperancia de los intentos de reducirlos a una escritura uniforme” (Albó, 1988: 85) y, por último, en las actitudes de vergüenza y autorrepresión de los hablantes hacia la lengua del grupo que los identifica con los sectores más desprestigiados de la sociedad de la cual forman parte.

Chiodi y Loncón (1999) analizan diversos factores lingüísticos (empobrecimiento del léxico, escasa diversidad y renovación de registros) y sociolingüísticos (persistencia de la oralidad, bajo prestigio y debilitamiento de la lealtad lingüística) que caracterizan el desequilibrio funcional entre español y mapudungún y ponen de manifiesto la condición de este último como idioma oprimido. El desplazamiento es observable en diversos ámbitos de interacción, incluso en aquéllos donde la presencia y uso del mapudungún son considerados decisivos por la propia comunidad, tales como la socialización familiar y las ceremonias rituales 
(Chiodi y Loncón, op. cit.). La dimensión más dramática en que se manifiesta el desplazamiento es la disminución del número de hablantes ${ }^{3}$.

En el marco de las relaciones interétnicas también se pueden identificar fenómenos sociolingüísticos contrarios a la tendencia dominante y que pueden relacionarse con la tradición histórica de resistencia cultural que ha caracterizado a las sociedades indoamericanas. Albó (1998), por ejemplo, muestra cómo la apropiación de la radiodifusión por parte de comunidades indígenas de Bolivia ha permitido insertar el quechua y el aymara en ámbitos de uso que eran de dominio exclusivo de la lengua nacional. Muñoz (2006b), en tanto, analiza los modelos de integración adoptados por migrantes mixtecos y zapotecos en California y discute los nuevos sentidos que adquiere la conservación etnolingüística en estos contextos. Para el caso mapuche, como ya se dijo, se parte de la premisa de que las innovaciones culturales por lo general conducen a la asimilación y, por tanto, pérdida de rasgos culturales identificatorios. Visiones divergentes a esta tendencia general pueden encontrarse en Sepúlveda (1984) y Durán y Ramos (1987). Algunos hechos sociolingüísticos que admiten una doble mirada son el bilingüismo extendido en los portadores del conocimiento tradicional y la apropiación de la cultura escrita por sectores específicos de la población mapuche. Desde nuestra perspectiva, son ejemplos de una sociedad que paulatinamente se aleja del culturalismo radical que consideraba los formatos tradicionales de transmisión cultural y la oralidad excluyente como únicos medios para su reproducción y continuidad.

\section{VIGENCIA DEL MAPUDUNGÚN EN ESPACIOS URBANOS}

Las investigaciones sobre las condiciones de uso del mapudungún en espacios urbanos chilenos coinciden en señalar un panorama desalentador respecto de la vigencia de esta lengua entre la población urbana ${ }^{4}$. Por ejemplo, Zúñiga (2007) señala que menos del $2 \%$ de los mapuches urbanos declara hablar la lengua a diario (lo que equivale a un 15\% de los hablantes urbanos). En cuanto al uso de la lengua en la interacción con niños pequeños, sólo un 2,4\% de los hablantes urbanos declara una práctica habitual del mapudungún con las nuevas generaciones. Las conclusiones del autor son transparentes en relación con los datos que analiza: "Todo apunta en la dirección de una lengua minoritaria que está siendo abandonada por un número sustancial de sus hablantes" (Zúñiga, 2007: 22).

En tanto, Giannelli (2008b) obtiene resultados similares en una investigación que utiliza cuestionarios autoevaluativos con mapuches urbanos de Santiago.

${ }^{3}$ Zúñiga (2007) propone cifras de hablantes de mapudungún en Chile entre los 140 mil y los 260 mil, según si en el conteo se incluye o no a los bilingües pasivos.

${ }^{4}$ Véase Lagos (2004); Tova Saul (2005); Zúñiga (2007) y Giannelli (2008b). 
Giannelli observa una inconsistencia sistemática entre la práctica cotidiana de la lengua, por un lado, y un conjunto de actitudes positivas -aunque abstractas y generales- por otro, que tanto hablantes como no hablantes expresan en relación con el sentido que otorgan a la lengua como símbolo de la identidad mapuche. Ampliando el foco hacia el contexto indoamericano, Giannelli (2008b) interpreta esta observación en términos de una pugna no resuelta "por una hegemonía efectiva" que enfrenta a la sociedad occidental y a las culturas y modos de vida tradicionales (y sus reinterpretaciones modernas) desde el origen mismo en que esta relación se ha implantado. Giannelli (2008b) plantea la posibilidad de una síntesis entre estas presiones contrapuestas (homologación y diferenciación), de la que podría derivarse un estatus funcional de relativa estabilidad para el mapudungún, aunque restringido a los contextos rituales y las interacciones de carácter privado e intraétnico.

Estas investigaciones constituyen un primer acercamiento a la situación actual de uso del mapudungún en espacios urbanos. Los resultados que aportan son de indudable valor para comprender la magnitud de los procesos en curso. Las proyecciones indican un escenario crítico respecto de la continuidad del mapudungún en el medio urbano. No obstante, creemos necesario complementar el enfoque de estos estudios integrando la visión que los propios hablantes tienen respecto de los procesos sociolingüísticos que les afectan. En otra ocasión, hemos planteado la necesidad de vincular la discusión antropológica sobre identidad mapuche urbana con los asuntos propiamente sociolingüísticos (uso, adquisición, transmisión y recuperación de la lengua), situando estos últimos en la perspectiva de eventuales contrapesos al modelo diglósico imperante (Wittig, en prensa). En una línea similar a la planteada por Durán, Catriquir y Hernández (2007), creemos que las evaluaciones referidas a la funcionalidad y/o continuidad de las lenguas indígenas (minorizadas u oprimidas) deben ir más allá del examen de datos sociolingüísticos convencionales. Como sostiene Golluscio (2006), el debate debe situarse en algún punto de intersección entre las relaciones de poder y hegemonía específicas de la diglosia indoamericana y los sentidos de pertenencia y devenir que representa una lengua para los miembros de una comunidad.

\section{LA INVESTIGACIÓN}

Durante los años 2006 y 2007 desarrollamos un trabajo de investigación con hablantes urbanos en el que nos propusimos, por una parte, describir las pautas de uso y transmisión del mapudungún y, por otra, analizar los vínculos que los hablantes establecen con esta lengua en el contexto de la experiencia migratoria y urbana. La investigación se planteó en base a un diseño mixto, que integra métodos y procedimientos cuantitativos y cualitativos. En este artículo desarrollamos una 
primera aproximación a los resultados de la fase cualitativa de esta investigación. En concreto, nos proponemos analizar:

a) Las representaciones que los hablantes urbanos construyen respecto del lof o comunidad en tanto espacio ideal para el uso y continuidad del mapudungún.

b) Las representaciones referidas a los procesos de adquisición y recuperación del mapudungún en el marco de la experiencia urbana.

La investigación se realizó mediante entrevistas semiestructuradas con hablantes urbanos de Temuco, Concepción y Santiago. Como criterios de selección se fijaron la autoadscripción étnica y la condición de hablante de mapudungún. La selección de los participantes se llevó a cabo con la colaboración de dirigentes urbanos y profesores de mapudungún, que estaban en posición de identificar y proponer los contactos iniciales. La configuración final de la nómina de participantes se desarrolló mediante muestreo en cadena (Johnstone, 2000). La interacción con los entrevistados se realizó en un clima de cordialidad, principalmente en el domicilio de éstos y en compañía de otros miembros del grupo familiar. En la interacción registramos testimonios y argumentaciones particulares sobre el valor del mapudungún en distintos episodios de la vida del hablante, especialmente en relación con su experiencia migratoria y la condición urbana actual.

En total, registramos 40 entrevistas, 14 en Concepción, 8 en Santiago, y 18 en Temuco. Entrevistamos a 24 hombres y 16 mujeres, con una edad promedio de 44 años. De los participantes, 27 son migrantes de primera generación; 9 corresponden al perfil de migrante de doble residencia; y, por último, 4 califican como urbanos de segunda generación. En cuanto a la lengua materna, 22 declaran el mapudungún como primera lengua excluyente; 8 señalan la adquisición simultánea de ambas lenguas. Por último, 12 hablantes adquirieron el mapudungún como segunda lengua, en edades que oscilan entre los 10 y los 32 años, y por lo general en el medio urbano.

\subsection{La ciudad y el lof en las representaciones de los hablantes urbanos}

Un dato que nos sirve de punto de partida es la identificación consistente y generalizada del lof o comunidad como principal espacio de interacción en mapudungún en la vida cotidiana actual de nuestros entrevistados (hablantes urbanos que no sólo declaran actitudes positivas hacia la lengua, sino también una práctica cotidiana consecuente con dicha valoración). A ello se agrega que buena parte de los hablantes llevan varios años, incluso décadas, de residencia urbana y en algunos casos sus contactos con la comunidad de origen se remiten a visitas esporádicas o irregulares, situación que se agudiza con las distancias geográficas que los separan 
de estas comunidades (principalmente en el caso de Santiago; en menor medida, en el caso de Concepción).

Esta situación paradojal permite algunas lecturas posibles. En un primer plano, vemos en estas declaraciones una manifestación implícita de los obstáculos que enfrentan los hablantes urbanos para poder utilizar el mapudungún en sus interacciones cotidianas. En un sentido general, lo anterior alude al desequilibrio funcional que regula la elección de lenguas y que se traduce en un número reducido de contextos comunicativos en que el hablante urbano siente que puede y debe usar el mapudungún (Giannelli, 2008b).

Del mismo modo, en directa relación con el escenario diglósico -y potenciándolo- el abandono de la práctica del mapudungún en instancias públicas ha sido una repuesta deliberada con miras a ocultar la propia identidad y así evitar el peso del estigma social y la discriminación. Declaraciones de este tipo actualizan representaciones instaladas en el imaginario colectivo mapuche. La comunidad es idealizada en abierta oposición al contexto urbano; permanece anclada en la memoria colectiva del mapuche urbano (Aravena, 2003) en tanto espacio esencial para la formación, reproducción y recreación de la identidad a través de la palabra y de las pautas endógenas de interacción social.

Lo anterior, sin embargo, no implica negar el valor que pueden tener las comunidades en tanto áreas de refugio o espacios de reproducción cultural, aun cuando la 'relidad' parece decir otra cosa. Las palabras de Chiodi y Loncón son claras al respecto:

No cabe duda de que actualmente el mapuzugun tiene aún vigencia en la comunidad rural, donde encuentra un ambiente más propicio para su continuidad. Pero de un lado, la comunidad es un espacio social mapuche que parece empequeñecerse cada vez más, debido a la migración, a la urbanización y a la falta de decididas políticas de desarrollo de la agricultura campesina, y del otro, como ya hemos dicho, también en la comunidad recurrir al castellano se ha hecho cada vez más frecuente e indispensable (Chiodi y Loncón, 1999: 43).

Sobre la base de los datos sociolingüísticos disponibles y en función de los mismos testimonios de nuestros entrevistados se va presentando un cuadro de mayor complejidad que una simple oposición entre espacio urbano y comunidad, con que inicialmente se intentó caracterizar el problema de la funcionalidad de la lengua mapuche en el ámbito urbano:

"Hay algunos que dicen que tienen la fortuna, que dicen que encuentran muchas personas que se manejan bien en el idioma y traen esa riqueza cuando van a sus lof, de haber compartido harto con personas en su idioma, pero hay otros tantos que dicen que no, porque nuestra gente está como... perdiendo su tradición en 
la religión evangélica... se han hecho muchas iglesias evangélicas, dicen, y no quieren saber nada de nuestra cultura, y hay personas que traen esa pena en su espíritu cuando van a buscar fortalecimiento para allá y se encuentran con algo, que es una tremenda barrera en su contra" $(\text { SM39) })^{5}$.

Testimonios como el anterior dan cuenta de las influencias que pueden tener en las pautas de uso del mapudungún ciertos elementos culturales ajenos que irrumpieron, se instalaron y aún permanecen al interior de las llamadas comunidades tradicionales (Durán y Quidel, 2007). Es lo que Bonfil Batalla (1989) denominó "cultura impuesta", en alusión a los campos de cultura (escuela, iglesias, medios de comunicación, entre otros) en que los individuos y el grupo pierden capacidad de control y de decisión, lo que les impide intervenir y regular, en este caso concreto, el uso de la lengua en los espacios de interacción social no tradicionales.

En una línea similar, otros testimonios remiten a la distancia o rechazo que aún se manifiesta en algunas comunidades hacia los mapuches urbanos. Esta tensión tiene su raíz en la idea de que el mapuche urbano tiende a 'ahuincarse', esto es, a alejarse parcial y gradualmente del ad mapu, de la costumbre mapuche. Uno de los planos más palpables en que se manifiesta este 'ahuincamiento lingüístico' y la consiguiente reacción que esta conducta genera, se observa en el manejo de las pautas culturales de interacción, principalmente el pentukun o pentukuwün ${ }^{6}$. En la interacción, estas pautas son establecidas por quienes continúan la costumbre o están en condiciones de hacerlo.

"A mí me tratan igual. ¿Será porque yo nací, me crié con ellos? Yo... converso con ellos también, pero dicen que... bueno, otros peñi, dicen que cuando ellos se van al campo y... como que igual hay otra manera de que a ellos los unan, por ejemplo, dicen... no sé, pero es otra manera de dirigirse a ellos... pero conmigo no, normal, ¿será porque hablo también? Yo llego allá y le digo “mari mari lamngen, mari mari peñi; ¿Chumleymi, peñi? ¿Kümeleymün? - ‘¿Cómo está?’ - ¿Chümley tami pu che? ¿Chumley tami lamngen? ¿Chumley tami choyün?” Todo eso... Entonces ahí yo pienso que hay una forma de uno de dirigirse a la gente mapuche, del campo o del sur..." (SH31).

No basta sólo con conocer la lengua y saber usarla como instrumento para la comunicación cotidiana. Se trata también de conocer y manejar las pautas endógenas de interacción, de desarrollar y cultivar una competencia pragmática que permita ejecutar discursos que, además de referir a elementos situacionales inme-

${ }^{5}$ Hemos optado por la utilización de un código para identificar a los hablantes. Este indica ciudad de residencia (S-C-T), sexo (M-H) y la edad cronológica.

6 "Diálogo ritual solemne que se ejecuta al comienzo de una visita o encuentro". En Glosario mapudungun-español elaborado por Fresia Mellico y publicado como Anexo en Golluscio (2006). 
diatos, ponen en escena ciertas prácticas culturales en torno a las cuales los miembros del grupo van construyendo y redefiniendo los sentidos de comunalidad que los vinculan (Golluscio, 2006). Los vínculos que los hablantes urbanos mantienen con sus comunidades de origen son muy diversos, pues están moldeados por sus experiencias migratorias o por las realidades socioculturales de las comunidades. Sin embargo, dentro de esta heterogeneidad es posible identificar algunos casos típicos.

Uno de éstos corresponde a los llamados "migrantes de doble residencia" (Bengoa, 1996), personas en permanente tránsito entre el medio rural y el urbano, que participan de redes sociales en ambos espacios y constituyen, por tanto, relaciones características de las comunidades translocales (Gundermann y González, 2008). En nuestros entrevistados, esta condición se presenta de manera más clara para los hablantes de Temuco y de las comunidades aledañas. Es una circunstancia que marca y diferencia notablemente sus posibilidades para desarrollar un repertorio de usos lingüísticos diferenciados en el sentido de Sepúlveda (1984) y que les permite interactuar con relativa fluidez en el tránsito constante entre uno y otro espacio.

Un caso diferente se presenta en los hablantes que vivieron su experiencia migratoria como una separación drástica de la comunidad de origen y al margen de las redes de apoyo que acogen y facilitan la inserción y adaptación al medio urbano. Estas circunstancias se observan con mayor nitidez en algunos hablantes sobre los 50 años de edad y entre quienes han formado parejas exogámicas. En algunos casos, su vinculación a organizaciones u otras instancias de interacción social con la comunidad mapuche urbana es mínima. Son hablantes que ocultan su identidad étnica y consecuentemente renuncian a la práctica del idioma reactivándola sólo en situaciones puntuales, como puede ser la visita ocasional de algún pariente o viajes irregulares que hacen a la comunidad de origen. Ciertamente la experiencia más dramática se observa en los casos en que las redes sociales de la familia o la comunidad se desintegran:

“...es que cuando la familia se separa, se muere, es como que igual ehh, es difícil después... por ejemplo si..., ya supongámosle que yo me hubiera casado con una persona que fuera mapuche y que le gustara de estar... cerca de una machi... a lo mejor hubiera sido lindo de seguir con lo mismo, con la costumbre, de estar yendo a hacer una fiesta, a una rogativa, o cualquier cosa... claro sería bonito, pero, como le digo, mientras tuve mi familia, duró poh... es como que se fue, murió mi abuelito, murió mi abuelita... ya como que ya... entonces murieron ellos, es como echar de menos ellos, es como echar de menos las cosas que uno hacía con ellos, pero más allá... sin ellos, uno dice, bueno, no queda otra cosa que conformarse con lo que uno tiene o ha logrado, igual, la costumbre siempre... siempre está esa nostalgia” (CM39). 
Hay hablantes a quienes en algún momento de su vida urbana se les presenta la disyuntiva entre resistencia cultural o asimilación; un "ahuincamiento" que puede ser provisorio, reversible, pero también definitivo. Quienes resisten o revierten el implacable designio de la asimilación buscan o generan las instancias sociales donde dar curso a su identidad mapuche. Junto con retomar la práctica del idioma ayudan también a otros miembros del grupo en búsquedas similares. De este modo, van asumiendo roles activos en una aparente renovación cíclica de las bases de la comunidad de habla desde el espacio urbano:

\begin{abstract}
"Cuando yo llegué, a los 34 años, dejé de hablar, ahora dos años que estoy hablando nuevamente. [¿Y por qué dejó de hablar?] Tú sabes que cuando uno llega a otra parte, cambia el sistema, el sistema de vivir, hay que adaptarse al sistema del winka, digamos, entonces me adapté, tanto me adapté que ya no hablé más mapuche, siendo mi señora mapuche también, no hablábamos y... después hice un curso pastoral mapuche, mapudungun, y me gustó. Dos años atrás lo hice, y en esos dos años 'no voy a perder las raíces, voy a rescatar mi tradición, nuestras costumbres, nuestras comidas, nuestra tradición, el we tripantü', qué se yo... y formamos una agrupación mapuche, llevamos de mayo hasta esta fecha... hemos hecho curso de mapudungun también, incluso yo quiero hacer ahora curso, o sea yo quiero enseñar, para eso estoy especializándome, para enseñarle a los peñi... pero hay mucha gente que están un poco perdidos, están muy ahuinca’o, digamos, muy achilenados" (SH56).
\end{abstract}

En el fragmento anterior se distinguen al menos tres representaciones con que el hablante conceptualiza el valor del mapudungún durante su experiencia urbana:

a) como elemento consustancial a la formación de la identidad mapuche que, una vez trasladado al medio urbano, el hablante decide anular, incluso en contextos de interacción estrictamente privados como la comunicación intrafamiliar;

b) como medio que le posibilita re-encontrar y re-asumir su identidad, en este caso concreto, en el seno de una institución ajena a los campos de la cultura tradicional mapuche;

c) como un saber que lo legitima en su entorno y lo faculta para re-orientar a otros mapuches urbanos en el encuentro de la identidad étnica a través de instancias formales de enseñanza y difusión de la lengua.

Desde nuestra perspectiva, estas representaciones, que corresponden también a tres momentos en la experiencia urbana del hablante, ponen en escena el carácter cíclico con que un sector de los mapuches asume su identificación étnico-cultural en el medio urbano. 


\subsection{Adquisición y recuperación del mapudungún en el espacio urbano}

Sin duda que el perfil específico de los hablantes está determinado por las condiciones de la interacción familiar y la socialización dentro del colectivo. Para el caso mapuche, este principio, por lo general, se ha aplicado a procesos 'convencionales' de adquisición, que consideran el desarrollo de competencias activas en la lengua desde la primera infancia. No obstante, algunas investigaciones dejan entrever la posibilidad de condiciones favorables para un desarrollo tardío de la competencia activa (Gundermann, 2005; Zúñiga, 2007). Lo anterior implica que a etapas iniciales de bilingüismo pasivo de extensión variable le sigue un desarrollo de habilidades lingüístico-comunicativas que permiten al sujeto participar progresivamente en interacciones grupales que se desarrollan parcialmente en mapudungún. Nuestros registros apuntan en esta dirección: 12 de los 40 entrevistados tienen el castellano como primera lengua excluyente. Estos hablantes declaran haber adquirido competencia activa en mapudungún entre los 10 y los 32 años de edad. En estos casos, el proceso de adquisición tiene lugar principalmente a partir de la experiencia urbana, como respuesta a los conflictos identitarios que se potencian con la experiencia migratoria.

La imagen convencional sugiere que la adquisición del mapudungún como primera lengua ${ }^{7}$ se produce en el contexto de la comunidad, en contacto directo y frecuente con los abuelos y, más importante aún, con la posibilidad de mantener una participación regular en las instancias de interacción social en que a través de la oralidad se adquiere y consolida el conocimiento cultural mapuche. Sin embargo, el solo hecho de haberse criado en un entorno favorable para la transmisión de la lengua y la cultura no basta para determinar los derroteros por los cuales transitará la identidad cultural y lingüística del hablante. Por ejemplo, una vez que éste se asienta en el medio urbano, la irregularidad o la falta de eventos de interacción en mapudungún tienen un efecto progresivo en la autopercepción de sus habilidades comunicativas.

"Bueno, yo empecé hablando el mapudungun, yo creo de guagua, o sea yo nací de padres mapuche hablándome en mapuche, en mapudungun siempre, entonces yo lo llevo de nacimiento esto... de chica... yo el castellano lo vine a hablar después de adulta, a hablar más... el castellano lo pude pronunciar mejor ya cuando lle-

\footnotetext{
${ }^{7}$ Un tópico que no ha sido debidamente abordado por las investigaciones que utilizan métodos convencionales (cuestionarios o censos sociolingüísticos) dice relación con la posición efectiva que ocupa el mapudungún en la transmisión y adquisición lingüística del niño. Todo indica que la adquisición del mapudungún como primera lengua exclusiva es una práctica en franco retroceso, de lo cual no se sigue necesariamente una actitud negativa hacia la transmisión y continuidad del mapudungún. Una interpretación alternativa sugiere un cambio en el patrón socio-comunicativo de la comunidad mapuche, inserta en un contexto social que exige el bilingüismo como medio que permite a los individuos interactuar tanto en la sociedad nacional como en la sociedad mapuche.
} 
gué a la ciudad y me costó... Entonces en las conversaciones, el acercamiento que yo tenía con... más, siempre mapudungun... entonces yo fui, como dijera yo, lo aprendí bien y después que salí, hablé el castellano y después del castellano como que me costó... volver a hablar mapuche... pero haber tenido la oportunidad de volver a hablarlo ahora como que me salió mejor, o sea como que yo,... como le dijera yo,... uno eh... modula mejor entre [incomprensible $]. .$. Entonces ahí aprendí bien el idioma..." (CM50).

En un marco de solidaridad recíproca motivada muchas veces por los conflictos culturales y las necesidades espirituales, algunos hablantes urbanos se asumen como agentes de cambio en las pautas de uso del mapudungún dentro del colectivo $-\mathrm{O}$ al menos dentro de sus redes de interlocutores inmediatas. El caso anterior corresponde a una hablante que emigró de su comunidad a los 20 años, sin haber recibido formación escolar, por lo que organiza su experiencia y sus relaciones con el mundo desde la "lógica de la oralidad" (Gallardo, 2001). En su caso, la autopercepción de las competencias en la lengua materna se renueva y potencia en el contexto urbano.

En una línea similar, situamos la experiencia de desarraigo de la cultura y la lengua mapuche que un hablante vincula directamente con su ingreso a la educación formal, y que no se revierte sino hasta el término de su formación profesional. Es a partir de este momento que asume, según sus palabras, un rol activo en el impulso y la difusión de las prácticas culturales mapuches en la ciudad:

“...esto de participar activamente con mis papás en las ceremonias mapuches, ngillatun, palin, ngülamtun, kamarikun, todos esos eventos más sociales en las comunidades, no tuve oportunidad de hacerlo, en realidad, porque por ser niño menor... siempre los chicos nos quedábamos en las casas, y como soy el último, con mayor razón... Después empecé a educarme en la Educación Básica en un colegio de campo y ahí, en realidad, me desarraigué diría casi totalmente de lo que es la cultura mapuche o del conocimiento de la lengua porque ya el idioma mapuzungun ya no fue una prioridad en el colegio... Así me fui desarraigando de todo lo mapuche, del idioma, de todos estos eventos que nunca tuve posibilidad de participar cuando niño; curiosamente en Santiago vine a relacionarme y participar activamente y también ser un fuerte impulsor de esas prácticas, cuando ya había terminado la media, cuando había terminado mis estudios superiores" (SH35).

Los casos más significativos por la intensidad que representa el conflicto identitario corresponden a quienes declaran haber alcanzado la condición de hablante en su juventud o incluso en la edad adulta. Es lo que se aprecia en el testimonio de una hablante, que tras un largo período vinculada a un movimiento evangélico, 
señala haber asumido y comprendido el sentido de pertenencia que la une a los demás miembros del grupo:

“...eso sucede por ahí por el año 2000 más o menos, yo tenía una vecina que siempre me invitaba a participar en reuniones y me decía 'hay puros hermanos mapuche y nos reunimos, hacemos cosas, talleres, compartimos, comidas típicas' y de primera yo me negaba también por esto de la mentalidad que traía y un día me decidí a llegar hasta allá. Y cuando vi puras personas mapuche sentí que eso era un complemento muy fuerte que había ahí, que yo pertenecía ahí, que no tendría por qué estar en otro lado. Sentí que ése era un lugar propio y que realmente debía estar ahí. Más cuando las veía hacer purun a las lamngenes de repente todas con su vestimenta, sus atuendos, sentí que hablaban el idioma, y fue como una alegría muy íntima que sentí, y una fuerza y unas ganas de participar también, y así me junté con el grupo...” (SM39)

\section{CONCLUSIONES}

El examen de las condiciones de uso y transmisión del mapudungún, tanto en ámbitos rurales como urbanos, motiva justificadamente la preocupación de los especialistas y de la misma comunidad de hablantes respecto de la vitalidad de la lengua en el mediano plazo. Desde nuestro punto de vista, los resultados de investigaciones que utilizan métodos cuantitativos y enfoques macro-sociolingüísticos admiten planteamientos divergentes. Tomando como punto de partida datos de características similares, proponemos analizar los vínculos entre los procesos de identidad étnica en contexto urbano, por una parte, y la práctica lingüística de los hablantes urbanos, por otra. Este enfoque se basa en fragmentos de discurso reflexivo y testimonial sobre su experiencia migratoria y urbana. Estos discursos permiten acceder a representaciones de los hablantes urbanos de mapudungún en relación con los usos y significados que asignan a la lengua en su experiencia migratoria y su actual condición urbana ${ }^{8}$. En este itinerario intentamos encontrar explicaciones alternativas para un panorama sociolingüístico que desde hace algunos años se concibe como irreversible 9 . En una visión de conjunto, estos discursos ponen en entredicho la premisa del desarraigo cultural y consecuente abandono de la lengua por parte de los hablantes que se insertan en el mundo urbano.

Bajo un prisma constructivista, no esencialista de las identidades, que reconoce en ellas un carácter estratégico y situacional, la identidad étnica de los mapuches urbanos emerge desde un entramado de relaciones de alteridad: procesos de auto-

\footnotetext{
${ }^{8}$ Una propuesta similar se desarrolla en Muñoz Cruz (2006a).

${ }^{9} \mathrm{Al}$ respecto, véase Gundermann et al. (2009).
} 
identificación y de diferenciación de los otros (Aravena, 1999 y 2002; Peyser, 2003). Las formas de identificación que los mapuches urbanos establecen con el mapudungún trascienden la dimensión aparentemente objetiva del dato sociolingüístico convencional, instalándose en el plano de las relaciones simbólicas e ideológicas en que se funda su noción de comunidad. La identificación con el mapudungún es una dimensión particular de la identidad étnica de los mapuches urbanos, cuya evaluación debe ir más allá de la constatación de datos respecto del uso (o desuso) de la lengua y las funciones comunicativas que estos usos puedan cumplir. La lengua opera como mecanismo o institución social que permite establecer o acentuar las relaciones de pertenencia, y no como atributo esencial o excluyente de una determinada identidad étnica.

La identificación del mapuche con el mapudungún se vincula con el origen y los antepasados de la persona ${ }^{10} \mathrm{y}$ se moldea como respuesta a las relaciones de tensión que los hablantes mantienen, según sea el caso, con la comunidad de origen, con la sociedad chilena y urbana en general, y con la mayoría no-hablante que compone la comunidad mapuche urbana.

El itinerario de análisis permitió identificar también algunos fenómenos emergentes que merecen ser tratados a fondo en otra oportunidad. Nos referimos a la transición del bilingüismo pasivo al activo que caracterizaría el desarrollo de las habilidades y competencias lingüístico-pragmáticas de un determinado grupo de hablantes; la configuración de espacios de interacción en mapudungún en el contexto urbano como respuesta a la desintegración de las redes familiares y sociales del lof o comunidad; y, por último, el curso cíclico con que algunos hablantes experimentan su identificación étnica y lingüística.

Las constataciones anteriores podrían tomarse como manifestaciones iniciales de un cambio progresivo en el patrón de bilingüismo, que en términos concretos podría traducirse en un predominio de los hablantes de mapudungún como segunda lengua. En directa relación con este punto, es posible que los procesos de adquisición se apoyen cada vez más en formas mediadas y, por tanto, más intelectualizadas de la lengua. Del mismo modo, se verificaría una expansión gradual de estos procesos hacia espacios de socialización no tradicionales, como la escuela, la agrupación urbana, las redes sociopolíticas, entre otros.

Las investigaciones sociolingüísticas referidas a las condiciones de uso del mapudungún y sus proyecciones deben abordar de manera crítica los objetos y campos de acción que la disciplina ha redefinido en virtud de nuevas realidades

${ }^{10}$ Esto alude directamente a la idea del küpalme, concepto que en la cosmovisión mapuche se entiende como "la manifestación del püjü (espíritu) de uno de los antepasados del che (la persona). Este vínculo con los antepasados, así como la formación cultural de la familia y del lof van determinando las características psicológicas de la persona... El küpalme otorga un rol a cada persona y actuar, y de acuerdo a ese rol garantizan o aseguran un bienestar interno para la persona, lo que trae consigo un küme felen (estar bien)" (Huenchulaf, 2006: 24). 
empíricas. Como plantea Gumperz, se debe reexaminar la validez y aceptación de algunas premisas sociolingüísticas, por cuanto:

Seguir asumiendo que el conocimiento lingüístico radica principalmente en comunidades idealmente uniformes y, por lo tanto, hipotéticas - comunidades constituidas por hablantes que comparten un conocimiento perfecto acerca de lo que es significativo de sus lenguas - es problemático... significa incurrir en una especie de reduccionismo y, por lo tanto, negar la verdadera condición de la cooperación humana que, finalmente, es la que posibilita la vida social organizada (Gumperz, 1996: 35).

En este trabajo hemos expuesto los primeros planteamientos de un punto de vista alternativo a las condiciones actuales de uso y transmisión del mapudungún en espacios urbanos chilenos. La dimensión empírica de nuestra propuesta se sustenta en el discurso reflexivo y los testimonios de hablantes urbanos referidos a los significados que adquiere el mapudungún en el tránsito migratorio y la experiencia urbana. Nuestra perspectiva no pretende pasar por alto la gravedad de la situación actual (por ejemplo, los niveles mínimos de transmisión intergeneracional), como tampoco suponer que el conjunto de datos sobre el que se funda nuestro trabajo constituya una prueba empírica suficiente para afirmar la existencia de procesos sociolingüísticos capaces de revertir la situación de desplazamiento y subordinación que caracteriza al mapudungún en su relación con el español.

Determinar los caminos por donde pueda derivar la situación actual es asunto que de momento sólo puede esbozarse tentativamente. Frente a las distintas percepciones expuestas, entre otros, por Zúñiga (2007), Giannelli (2008b) y Gundermann et al. (2009), planteamos nuestro punto de vista, que implica una concepción de las prácticas lingüísticas de los hablantes urbanos en tanto estrategias de resistencia a la tendencia general de desplazamiento lingüístico y hegemonía cultural. A nivel microsocial, estas prácticas deben contextualizarse en la red de relaciones interétnicas en que el hablante se halla inmerso. La práctica lingüística según como la describen los propios hablantes responde a esfuerzos deliberados con que los sujetos buscan contener las consecuencias socioculturales inmediatas de un escenario diglósico que limita los ámbitos de uso de la lengua mapuche y pone en riesgo su continuidad. En el nivel macro del fenómeno sociolingüístico, probablemente el alcance de estas respuestas sea limitado e incluso marginal; pero es en el nivel microsocial de las prácticas e ideologías lingüísticas que se constituyen en testimonios de afirmación, difusión y eventual fortalecimiento de la identidad lingüística de los mapuches urbanos. Ese es el valor que vemos en las reflexiones y testimonios aquí comentados. 


\section{REFERENCIAS}

Albó, Xavier. 1988. "El futuro de los idiomas oprimidos". En Oralndi, Eni P. (edit). Política lingüistica na América Latina. Campinas: Pontes, pp. 75-104. Albó, Xavier. 1998. "Expresión indígena, diglosia y medios de comunicación". En López, L. E. y Jung, I. (comp.) Sobre las huellas de la voz. Madrid: Morata, pp. 126-156.

Ancán, José. 1994. "Los urbanos, un nuevo sector dentro de la sociedad mapuche contemporánea”, en Pentukun 1, pp. 5-15.

Aravena, Andrea. 1999. "La identidad indígena en los medios urbanos". En Boccara, G. y Galindo, S. (edit.) Lógica mestiza en América. Temuco: Instituto de Estudios Indígenas - UFRO, pp. 165-199.

Aravena, Andrea. 2002. "Los Mapuche-Warriache: migración e identidad mapuche urbana en el siglo XX". En Boccara, G. (ed.) Colonización, resistencia y mestizaje en las Américas. Quito: Abya-Yala, pp. 359-385.

Aravena, Andrea. 2003. "El rol de la memoria colectiva y la memoria individual en la conversión identitaria mapuche", en Estudios atacameños 26, pp. 89-96.

Barth, Frederik. 1998. [1969]. "Introduction". En Barth, F. (ed.) Ethnic groups and boundaries. The social organization of cultural difference. Long Grove, IL: Waveland Press, pp. 9-38.

Bartolomé, Miguel. 2006. "Los laberintos de la identidad. Procesos identitarios en las poblaciones indígenas", en Avá 9, pp. 28-48.

Bengoa, José. 1996. "Población, familia y migración mapuche. Los impactos de la modernización en la sociedad mapuche, 1982-1985", en Pentukun 6, pp. 9-28.

Bengoa, José. 2000. La emergencia indígena en América Latina. México y Santiago: Fondo de Cultura Económica.

Bengoa, José. 2002. "La invención de las minorías: las identidades étnicas en un mundo globalizado", en Revista de la Academia 7, pp. 9-37.

Bonfil Batalla, G. 1989. "La teoría del control cultural en el estudio de los procesos étnicos", en Ariasana 10, pp. 5-36.

Calvet, Louis-Jean. 2005 [1974]. Lingüistica y colonialismo. Breve tratado de glotofagía. Buenos Aires: Fondo de Cultura Económica. [1974. Linguistique et colonialismo. Pettit traité de glottophagie. París: Payot].

Chiodi, F. y Loncón, E. 1999. Crear nuevas palabras. Innovación y expansión de los recursos lexicales de la lengua mapuche. Temuco: Instituto de Estudios Indígenas-CONADI.

Curivil, Ramón. 1999. "Procesos de reetnificación de los mapuches de Santiago". Tesis de Maestría en Ciencias Sociales. Santiago, Chile: Universidad Academia de Humanismo Cristiano. Santiago de Chile.

Durán, T; Catriquir, D. y Hernández, A. 2007. "Revitalización del mapuzugun. 
Una visión crítica desde la educación intercultural, la sociolingüística y la antropología”. En Durán, T.; Catriquir, D. y Hernández, A. (compiladores) Patrimonio cultural mapunche. Volumen 1. Temuco: Editorial UC Temuco, pp. 107-125.

Durán, Teresa y Ramos, Nelly. 1987. "Incorporación del español por los mapuches del centro-sur de Chile durante el siglo XIX", en Lenguas Modernas 14, pp. 179-196.

Durán, Teresa y Quidel, José. 2007. "Reducción y comunidad. Visión externa al lof che y al lof mapu”. En Durán, T.; Catriquir, D. y Hernández, A. (compiladores) Patrimonio cultural mapunche. Volumen 3. Temuco: Editorial UC Temuco, pp. 415-441.

Fasold, Ralph. 1996. La sociolingüistica de la sociedad. Madrid: Visor.

Ferguson Charles. 1974 [1959]. "Diglosia”. En Lastra, Y. y Garvin, P. Antología de estudios de etnología y sociolingüistica. México: UNAM, pp. 247-265.

Fishmann, Joshua. 1982. Sociología del lenguaje. Madrid: Cátedra.

Gallardo, Andrés. 2001. "La lógica de la oralidad", en Aisthesis 34, pp. 92100.

Giannelli, Luciano. 2008a. "Dominios y redes de empleo del mapuzugun en el marco rural mapuche", en Signos Lingüísticos 10(5), pp. 99-122.

Giannelli, Luciano. 2008b. "La lengua nativa entre los mapuches urbanizados de Santiago de Chile. Un ejemplo de análisis en el marco de la hegemonía lingüístico-cultural", en NAE 24, pp. 23-31.

Gissi, Nicolás. 2002. "Los mapuche en el Santiago del siglo XXI: desde la ciudadanía política a la demanda por el reconocimiento", en Werkén 3, pp. 5-19.

Golluscio, Lucía. 2006. El pueblo mapuche. Poéticas de pertenencia y devenir. Buenos Aires: Biblos.

Gumperz, John. 1996. "El significado de la diversidad lingüística y cultural en un contexto post-moderno". En Muñoz, H. y Lewin, P. (comp.) El significado de la diversidad lingüistica y cultural. México: UAM - INAH, pp. 33-48.

Gundermann, Hans. 2005. "Estudio del contexto sociolingüístico de comunidades aymaras, atacameñas y mapuche de Chile". En Vergara, J. y Gundermann, H. (editores): Descripción del contexto sociolingüistico en comunidades indígenas de Chile, Santiago: Programa EIB MINEDUC - Programa Orígenes, pp. 1397.

Gundermann, H. y González, H. 2008. "Pautas de integración regional, migración, movilidad y redes sociales en los pueblos indígenas de Chile", en Universum 23 (1), pp. 80-113.

Gundermann, Hans, Jaqueline Canihuan, Alejandro Clavería y César Faúndez. 2008. Perfil sociolingüistico de comunidades mapuches de la Región del Biobio, Araucanía, los Ríos y los Lagos. Informe de Investigación. Santiago: CONADI - UTEM. 
Gundermann, Hans, Jaqueline Canihuan, Alejandro Clavería y César Faúndez. 2009. "Permanencia y desplazamiento, hipótesis acerca de la vitalidad del mapuzugun”, en RLA 47(1), pp. 37-60.

Hamel, Rainer E. 1988. "La política del lenguaje y el conflicto interétnico. Problemas de investigación sociolingüística”. En Oralndi, Eni P. (edit). Política lingüistica na America Latina. Campinas: Pontes, pp. 41-75.

Huenchulaf, Ernesto. 2006. "Cosmovisión Mapuche". En Material de Apoyo a Talleres de Promoción de Derecho Indigena. Temuco: Lonko Kilapang, pp. 9-25.

Johnstone, Bárbara. 2000. Qualitative methods in sociolinguistics. New York: Oxford University Press.

Lagos, Cristián. 2004. "La vitalidad lingüística del mapudungún en Santiago de Chile, sus factores determinantes y consecuencias socioculturales. Estudio exploratorio desde una perspectiva socio y etnolingüística”. Tesis para optar al grado de Magíster en Lingüística. Santiago, Chile: Universidad de Chile.

Marimán, Pedro. 1997. "La diáspora mapuche: una reflexión política", en Liwen 4, pp. 216-223.

Muñoz Cruz, Héctor. 2006a. "Cambio sociolingüístico y experiencias interculturales desde discursos autobiográficos de hablantes de lenguas indígenas", en Cuadernos Interculturales 7, pp. 23-48.

Muñoz Cruz, Héctor. 2006b. "Inmigración de indígenas a Estados Unidos: el dilema entre la americanización y la etnodiversidad”. En Muñoz, Héctor (coord.) Lenguas y educación en fenómenos multiculturales. México: UAM Iztapalapa-UPN, pp. 113-147.

Peyser, Alexia. 2003. "Desarrollo, cultura e identidad. El caso del mapuche urbano en Chile. Elementos y estrategias identitarias en el discurso indígena urbano". Tesis presentada para la obtención del grado de Doctor en Ciencias Sociales. Universidad Católica de Lovaina.

Salas, Adalberto. 1987. "Hablar en mapuche es vivir en mapuche. Especificidad de la relación lengua/cultura”, en $R L A 25$, pp. 27-35.

Sepúlveda, Gastón. 1984. "Vitalidad etnolingüística de la lengua araucana (1)". Cultura, Hombre, Sociedad vol. 1, pp. 223-262.

Tova Saul, Emily. 2005. Language in danger? The case of mapudungu in Temuco, Chile. B.A. in Language and Applied Linguistics, Griffith University.

Varas Insunza, José M. 2005. "La creación de la identidad étnica urbana: etnificación y etnogénesis del movimiento mapuche urbano organizado en la ciudad de Santiago 1990-2000". Tesis de Magíster en Antropología y Desarrollo. Santiago, Chile: Facultad de Ciencias Sociales, Universidad de Chile.

Wittig, Fernando (en prensa). En torno a la vigencia del mapudungún en Chile: la nueva realidad urbana y el pronóstico de los especialistas. Actas del VI Encuentro de Lenguas Aborígenes y Extranjeras, agosto de 2007. Salta: Universidad Nacional de Salta. 
Zimmermann, Klaus. 1999. Política del lenguaje y planificación para los pueblos amerindios: Ensayos de ecología lingüistica. Madrid/Frankfurt: IberoamericanaVervuert Verlag.

Zúñiga, Fernando. 2007. "Mapudunguwelaymi am? ‘'Acaso ya no hablas mapudungun?' Acerca del estado actual de la lengua mapuche”, en Estudios Públicos 105, pp. 9-24. 